\title{
Sugar-Sweetened Beverages Consumption Positively Associated with the Risks of Obesity and Hypertriglyceridemia Among Children Aged 7-18 Years in South China
}

\author{
Baoting $\mathrm{He}^{1}$, Weiqing Long ${ }^{2}$, Xiuhong $\mathrm{Li}^{1}$, Wenhan Yang ${ }^{1}$, Yajun Chen ${ }^{1}$ and Yanna Zhu ${ }^{1}$ \\ ${ }^{1}$ Department of Maternal and Child Health, School of Public Health, Sun Yat-sen University, Guangzhou, China \\ ${ }^{2}$ Department of Clinical Laboratory, the First Affiliated Hospital of Sun Yat-sen University, Guangzhou, China
}

\begin{abstract}
Aims: Excessive consumption of sugar-sweetened beverages (SSBs) may increase the prevalence of obesity and other metabolic risk factors. However, data regarding the relationship between SSB consumption and metabolic risk factors are insufficient in Chinese children. Hence, we aimed to explore the association between SSB consumption and cardio-metabolic risk factors in children aged 7-18 years living in South China.

Methods: A cross-sectional study was conducted in a total of 2,032 children aged 7-18 years were enrolled, including 1,013 boys and 1,019 girls. Based on a multistage cluster sampling, five elementary and four secondary schools in Guangzhou, China were included. Fasting blood glucose levels, lipid profiles, and anthropometric characteristics were evaluated. Information on demography, dietary, and physical activities were self-reported.

Results: Overall, $34.7 \%$ participants were non-drinkers and $21.6 \%$ consumed more than $120 \mathrm{~mL} /$ day SSB. The body mass index $\left(19.43 \pm 0.18 \mathrm{~kg} / \mathrm{m}^{2}\right)$ and triglyceride concentration $(0.96 \pm 0.03$ $\mathrm{mmol} / \mathrm{L})$ were higher and high-density lipoprotein concentration $(1.32 \pm 0.31 \mathrm{mmol} / \mathrm{L})$ was lower in consumers than in non-consumers (all $P<0.001$ ). Furthermore, in contrast to non-consumers, the adjusted odds ratio of SSB consumption more than $120 \mathrm{~mL} /$ day was 2.08 (95\% CI: 1.21-3.54) for obesity, 1.83 (95\% CI: 1.25-2.69) for abdominal obesity, and 1.70 (95\% CI: 1.02-3.06) for hypertriglyceridemia in consumers.

Conclusion: A positive association between SSB consumption and the risks of obesity and hypertriglyceridemia was observed in children living in South China, which suggests that high SSB consumption enhances the risk of cardio-metabolic risk factors and the consequent cardio-metabolic diseases.
\end{abstract}

Key words: Sugar-sweetened beverages, Obesity, Lipid profile

Copyright@2018 Japan Atherosclerosis Society

This article is distributed under the terms of the latest version of CC BY-NC-SA defined by the Creative Commons Attribution License.

\section{Introduction}

With the rapid economic growth and drastic global shifts in diet and lifestyle, the prevalence of obesity and obesity-related cardiovascular risk factors in children, including hypertension and abnormal lipid and elevated fasting glucose levels, have increased evidently worldwide in the recent decades ${ }^{1-3)}$. According

Address for correspondence: Yanna Zhu, Department of Maternal and Child Health, School of Public Health, Sun Yat-sen University. No.74 Zhongshan Road II, Guangzhou, Guangdong Province, China, 510080

E-mail: zhuyn3@mail.sysu.edu.cn

Received: October 17, 2016

Accepted for publication: April 20, 2017 to the Chinese National Survey on Constitution and Health in Students, the combined prevalence of obesity and overweight in Chinese children aged 7-18 years had reached $19.2 \%$ in $2010^{4}$. Meanwhile, Chinese children have also experienced a significant increase in the prevalence of other cardiovascular risk factors, including hypertension, dyslipidemia, impaired fasting glucose, and metabolic syndrome (MetS) during the past several years ${ }^{5-8)}$. Considering that these health problems not only affect the metabolic and psychosocial status in the short term but also contribute to a higher risk for consequent cardiovascular diseases in adulthood, it is important to determine valid measures for the prevention of obesity and other cardiovascular disorders in children. 
Energy-dense diets, brought about by improved economic conditions, have been considered to be one of the determinants of the rapid increase of obesity as well as other cardiovascular risk factors ${ }^{9)}$. As one of the important types of energy-dense diets, excessive sugarsweetened beverages (SSBs) consumption may bring about heavy energy intake and would be strongly associated with obesity and obesity-related risk factors. Several studies have reported a positive relationship between SSB consumption and obesity and other cardiovascular risk factors in adults and children, while others have not ${ }^{10-14)}$. A study has revealed that an extra cup of SSB per day would increase the risk of obesity by 1.6 times in American children aged 11.7 years on average ${ }^{15)}$. A similar study on the relationship between excessive SSB consumption and obesity and other cardiovascular risk factors was limited to Chinese children. Most of the previous studies mainly focused on the frequency of SSB consumption and sugar and energy intake from SSB. Additionally, effective policies were put forth to control SSB consumption in other countries, such as an additional $20 \%$ tax on SSB in Australia ${ }^{16)}$, whereas no official measures were carried out in China. Therefore, we conducted this study mainly to estimate SSB consumption and to explore the relationship between daily SSB consumption and the risks of obesity and other cardiovascular risk factors in children living in South China to provide evidences to put forth SSB controlling policies in China.

\section{Methods}

\section{Study Design and Sample}

The study was designed as a cross-sectional study. Data were obtained from a baseline survey that was performed in a national multi-centered project on school-based health lifestyle interventions against obesity among Chinese children and adolescents during 2013 and 2014 ${ }^{17}$. The initial sample included 2,878 children recruited from five elementary and four secondary schools in Guangzhou. Children aged 7-18 years and those who completed the anthropometric measurement, questionnaire assessment, and blood sample collection were eligible to participate in this study $(n=2,157)$. Participants were excluded if they refused to finish anthropometric measurement, questionnaire assessment, and blood sample collection, if their data for SSB consumption were missing, or if they had acute or chronic diseases $(n=125)$. The final sample consisted of 2,032 children. The study was approved by the ethical committee of the Peking University. Written informed consents were obtained from both students and their legal guardians.

\section{Anthropometric Measurement}

Anthropometric measurements of height, weight, waist circumference, and blood pressure were all made by experienced clinicians and nurses according to standardized methods. Participants were requested to be in light clothing during the measurements. Height was measured to the nearest $0.1 \mathrm{~cm}$ using a fixed stadiometer. Weight was measured to the nearest $0.1 \mathrm{~kg}$ using a level scale and then body mass index (BMI) was calculated. Waist circumference was measured to the nearest $0.1 \mathrm{~cm}$ using a flexible tape in the standing position after a gentle respiration, taking the umbilical scar as the reference. The systolic and diastolic blood pressures of children were measured in a seated position using a sphygmomanometer. The meanof two consecutive measures was used in the analyses.

\section{Assessment of SSB Consumption and Lifestyle Factors}

The self-reported questionnaire in this study included questions regarding general demographic information (age and gender), physical activities (mainly including vigorous-intensity and moderate-intensity activities), sedentary behavior, sleep duration, dietary information, SSB consumption, and the attitudes of teachers and schools of the children toward SSB consumption. To estimate SSB consumption and frequency, the question was put forth as: "How many days and how many servings of SSB did you have last week? (SSB include carbonated drinks, juices, and sports and sweet tea beverages. One serving of SSB was approximately equal to $250 \mathrm{~mL}$.)". For dietary information, similar questions regarding the consumption of fruit, vegetable, and meat were asked (One serving of the fruit, vegetable, and meat was approximately equal to the palm size of an adult). Children were also asked questions regarding their teachers' and schools' attitudes toward SSB consumption, including "Does your teacher allow you to bring the SSB into the classroom?" and "Can you buy SSB in the canteen or the stores of your school?" For physical activities, moderate-intensity (those having 3-6 metabolic equivalents) and vigorous-intensity (those having $>6$ metabolic equivalents) activities were estimated by giving examples. The question asked was as follows: "How many days and how many hours per day did you perform vigorous-intensity (such as running, basketball, football, and physical fitness activities) and moderate-intensity (such as table tennis, moving something light, and dancing) activities last week?" For sedentary behavior, the question was as follows: "How many hours and minutes did you sit and lie (excluding sleeping) per day?" For sleeping duration, children were asked the question: "How many hours do you 
sleep per day? " Sleep duration per day was categorized into four groups $(<7.0,7-9,9-11$, and $>11 \mathrm{~h} /$ day). All these questions were previously tested and validated.

\section{Lipid and Glucose Concentrations in Serum}

Venous blood samples were drawn after an overnight fast. Both serum and plasma were collected by centrifugation at $3000 \mathrm{r} / \mathrm{min}$ for $10 \mathrm{~min}$ at $4{ }^{\circ} \mathrm{C}$ and thereafter, stored at $-80^{\circ} \mathrm{C}$ until analysis. The serum concentrations of glucose and lipids (triglyceride, highdensity and low-density lipoprotein cholesterol, and total cholesterol) were determined using commercial colorimetric kits (Biosino Biotechnology Company Ltd, Beijing, China) and an automated analyzer (Hitachi Co Ltd). These analyses were performed in specialty laboratories accredited by the Peking University. For all laboratory methods, the inter- and intra-assay coefficients of variation were below $5 \%$.

\section{Definition of Obesity and Other Cardio-Metabolic Risk Factors}

According to the guidelines of the Working Group on Obesity in China, obesity and overweight were defined as $\mathrm{BMI} \geq 95^{\text {th }}$ and $85^{\text {th }}$ percentile using ageand gender-specific cutoff points, respectively ${ }^{18,}{ }^{19)}$. Abdominal obesity was defined as $\mathrm{WC} \geq 90^{\text {th }}$ percentile using age and gender-specific cutoff points ${ }^{20)}$.

Other cardio-metabolic risk factors, including hypertension, abnormal fasting glucose and lipid levels, dyslipidemia, and MetS, were mainly defined using the MetS criteria proposed by Cook et $a l^{21)}$. Hypertension was defined as either SBP or DBP $\geq 90$ th percentile using age-, gender-, and height-specific cutoff points ${ }^{22}$. Elevated fasting glucose level was defined as the fasting glucose level $\geq 5.6 \mathrm{mmol} / \mathrm{L}$. Hypertriglyceridemia was defined as TG $\geq 1.7 \mathrm{mmol} / \mathrm{L}$. Hypercholesterolemia was defined as TC $\geq 5.18 \mathrm{mmol} / \mathrm{L}$. Dyslipidemia was defined as having one or more of the following abnormal lipids levels: TG $\geq 1.7 \mathrm{mmol} / \mathrm{L}$, $\mathrm{TC} \geq 5.18 \mathrm{mmol} / \mathrm{L}, \mathrm{HDL} \leq 1.03 \mathrm{mmol} / \mathrm{L}$, and $\mathrm{LDL}$ $\geq 3.36 \mathrm{mmol} / \mathrm{L}^{21,23)}$. MetS was defined as meeting three or more of the following criteria: abdominal obesity, high blood pressure, TG $\geq 1.7 \mathrm{mmol} / \mathrm{L}, \mathrm{HDL}-\mathrm{C} \leq 1.03$ $\mathrm{mmol} / \mathrm{L}$, and fasting serum glucose $\geq 5.6 \mathrm{mmol} / \mathrm{L}^{21)}$.

\section{Statistical Analysis}

The data bank was established by Epidata 3.0 software (The Epidata Association, Odense, Denmark). All statistical analyses were performed using SPSS 19.0 software (SPSS 19.0, Chicago, USA). Characteristics of the participants were first presented as number and percentage in different categories. The average SSB consumption among the categories of different characteristics was presented as mean and standard error. The quartiles calculated by the software were then applied to determine SSB consumption levels. Chi-square test was used to determine the difference between categorical variables, while $t$-test and oneway ANOVA were used for the comparison of continuous variables among the four SSB consumptions. Post hoc Dunnet's $t$-test was applied to examine the intergroup differences. Logistic regression was used to explore the association between SSB consumption and cardiovascular risk factors in both crude and adjusted models controlling for age, gender, and physical activities. A two-sided $P$-value $<0.05$ was considered significant.

\section{Results}

\section{SSB Consumption Among Categories of Different Characteristics}

A total of 2,032 children were included in this study, including 1,013 boys and 1,019 girls. Their age ranged from 6 to 18 years $(69.0 \%$ ranged from 6 to 12 years and $31.0 \%$ from 13 to 18 years). In these participants, $230(11.3 \%)$ children were overweight, $178(8.8 \%)$ were obese, and $423(20.8 \%)$ were with higher waist circumference. The mean SSB consumption in all participants was $90.45 \pm 3.55 \mathrm{~mL} /$ day. SSB consumption even reached $138.51 \pm 4.96 \mathrm{~mL} /$ day per consumer. Overall, 34.7\% participants were non-drinkers, $21.7 \%$ reported that they consumed more than $120 \mathrm{~mL}$ per day (which approximately equals more than 3 servings a week), and $9.5 \%$ consumed more than $250 \mathrm{~mL}$ per day. Table 1 shows SSB consumption of children in different categories of the characteristics including gender, age, nutritional status, fasting glucose level, lipid profile, their teacher's and school's attitude toward their SSB drinking behavior, moderate-to-vigorous physical activity, and sleeping duration. Children having higher SSB consumption were more likely to be boys and to have higher age and lower sleeping duration. Their SSB drinking behaviors were more likely to be not prohibited by their teachers and schools. However, no statistical significance in SSB consumption was revealed among children with different nutritional statuses, physical activities, and fasting glucose and lipids levels.

\section{Characteristics of the Participants Stratified by SSB Consumption}

Characteristics of the participants stratified by SSB consumption are shown in Table 2. Compared with that in the girls, the percentage of participants consuming more than $120 \mathrm{~mL} /$ day was significantly higher and percentage of non-drinkers was much lower 
Table 1. Sugar-sweetened beverage consumption and characteristics of the participants $(n=2032)$.

\begin{tabular}{|c|c|c|c|c|c|c|}
\hline \multirow{2}{*}{ Characteristics } & \multirow{2}{*}{ Categories } & \multicolumn{2}{|c|}{ Amount } & \multicolumn{2}{|c|}{ SSBs intake (ml/day) } & \multirow{2}{*}{$P$} \\
\hline & & $\mathrm{n}$ & $\%$ & mean & SE & \\
\hline \multirow[t]{2}{*}{ Gender } & Boys & 1013 & 49.9 & 112.04 & 6.03 & $<0.001$ \\
\hline & Girls & 1019 & 50.1 & 69.00 & 3.66 & \\
\hline \multirow[t]{2}{*}{ Age } & $6-12 y$ & 1402 & 69.0 & 64.21 & 2.95 & $<0.001$ \\
\hline & $13-18 y$ & 630 & 31.0 & 148.86 & 8.96 & \\
\hline \multirow[t]{4}{*}{$\mathrm{BMI}^{\mathrm{a}}$} & Underweight & 276 & 13.6 & 73.38 & 7.45 & 0.099 \\
\hline & Normal & 1345 & 66.2 & 90.00 & 4.61 & \\
\hline & Overweight & 230 & 11.3 & 106.91 & 10.58 & \\
\hline & Obese & 178 & 8.8 & 100.64 & 10.45 & \\
\hline \multirow[t]{2}{*}{$\mathrm{WC}^{\mathrm{b}}$} & Normal & 1609 & 79.2 & 87.78 & 4.05 & 0.143 \\
\hline & High & 423 & 20.8 & 100.61 & 7.35 & \\
\hline \multirow[t]{2}{*}{$\mathrm{TC}^{\mathrm{c}}$} & Normal & 1790 & 88.1 & 92.48 & 3.92 & 0.121 \\
\hline & High & 242 & 11.9 & 75.44 & 7.09 & \\
\hline \multirow[t]{2}{*}{ LDL-C $^{d}$} & Normal & 1877 & 92.4 & 91.32 & 3.77 & 0.274 \\
\hline & High & 155 & 7.6 & 79.97 & 9.62 & \\
\hline \multirow[t]{2}{*}{$\mathrm{TG}^{\mathrm{e}}$} & Normal & 1930 & 95.0 & 89.01 & 3.58 & 0.076 \\
\hline & High & 102 & 5.0 & 118.1 & 20.65 & \\
\hline \multirow[t]{2}{*}{ HDL-C ${ }^{f}$} & Normal & 1788 & 87.7 & 88.14 & 3.69 & 0.130 \\
\hline & Low & 249 & 12.3 & 107.04 & 11.90 & \\
\hline \multirow[t]{2}{*}{$\mathrm{SBP}^{\mathrm{g}}$} & Normal & 1917 & 94.3 & 91.03 & 3.72 & 0.342 \\
\hline & High & 115 & 5.7 & 80.90 & 9.94 & \\
\hline \multirow[t]{2}{*}{$\mathrm{DBP}^{\mathrm{h}}$} & Normal & 1904 & 93.7 & 90.86 & 3.71 & 0.659 \\
\hline & High & 128 & 6.3 & 84.40 & 11.75 & \\
\hline \multirow[t]{2}{*}{ FSG $^{\mathrm{i}}$} & Normal & 2002 & 98.5 & 90.20 & 3.59 & 0.566 \\
\hline & High & 30 & 1.5 & 107.14 & 27.82 & \\
\hline \multirow[t]{2}{*}{ Teacher's attitude } & Allow & 350 & 17.2 & 144.76 & 11.38 & $<0.001$ \\
\hline & Not allow & 1662 & 81.8 & 79.14 & 3.54 & \\
\hline \multirow[t]{2}{*}{ School's attitude } & Allow & 876 & 43.1 & 117.18 & 6.66 & $<0.001$ \\
\hline & Not allow & 1134 & 55.8 & 70.45 & 3.62 & \\
\hline \multirow[t]{2}{*}{$\mathrm{MVPA}^{j}$} & $<2 \mathrm{~h} /$ day & 1455 & 71.6 & 87.97 & 3.85 & 0.104 \\
\hline & $\geq 2 \mathrm{~h} /$ day & 170 & 8.4 & 115.8 & 16.54 & \\
\hline \multirow[t]{2}{*}{ Sleep duration } & $<9$ h/day & 1453 & 71.5 & 93.90 & 4.19 & $<0.001$ \\
\hline & $\geq 9 \mathrm{~h} /$ day & 410 & 20.2 & 61.15 & 7.08 & \\
\hline
\end{tabular}

${ }^{\mathrm{a}} \mathrm{BMI}=$ Body mass index

${ }^{\mathrm{b}} \mathrm{WC}=$ Waist circumference

${ }^{\mathrm{c}} \mathrm{TC}=$ Total cholesterol

${ }^{\mathrm{d}}$ LDL-C $=$ low-density lipid protein cholesterol

${ }^{\mathrm{e}} \mathrm{TG}=$ Triglyceride

${ }^{\mathrm{f}} \mathrm{HDL}=$ High-density lipid protein cholesterol

$\mathrm{g}_{\mathrm{SBP}}=$ Systolic blood pressure

${ }^{\mathrm{h}} \mathrm{DBP}=$ Diastolic blood pressure

${ }^{\mathrm{i}} \mathrm{FSG}=$ Fasting serum glucose

${ }^{\mathrm{j}} \mathrm{MVPA}=$ moderate to vigorous physical activities

in boys. When analyzing the consumption by different age groups, the number of participants who consumed more than $120 \mathrm{~mL} /$ day reached $37.6 \%$ in those aged between 13 and 18 years and $14.5 \%$ in those aged between 6 and 12 years. Participants whose SSB drinking behaviors were allowed had a higher percent- 
Table 2. Characteristics of the participants by Sugar-sweetened beverages consumption levels.

\begin{tabular}{|c|c|c|c|c|c|c|c|c|c|}
\hline \multirow{3}{*}{ Characteristics } & \multicolumn{8}{|c|}{ SSBs intake } & \multirow{3}{*}{$P$} \\
\hline & \multicolumn{2}{|c|}{$\begin{array}{l}\text { Non-drinker } \\
\quad(n=705)\end{array}$} & \multicolumn{2}{|c|}{$\begin{array}{c}-36 \mathrm{ml} / \text { day } \\
(n=403)\end{array}$} & \multicolumn{2}{|c|}{$\begin{array}{c}-120 \mathrm{ml} / \text { day } \\
(n=484)\end{array}$} & \multicolumn{2}{|c|}{$\begin{array}{c}\geq 120 \mathrm{ml} / \text { day } \\
\quad(n=440)\end{array}$} & \\
\hline & $\mathrm{N}$ or mean & $\%$ or $\mathrm{SE}$ & $\mathrm{N}$ or mean & $\%$ or $\mathrm{SE}$ & $\mathrm{N}$ or mean & $\%$ or $\mathrm{SE}$ & $\mathrm{N}$ or mean & $\%$ or $\mathrm{SE}$ & \\
\hline Gender & & & & & & & & & $<0.001$ \\
\hline Boys & 329 & 32.5 & 173 & 17.1 & 231 & 22.8 & $280^{*}$ & 27.6 & \\
\hline Girls & 376 & 36.9 & 230 & 22.6 & 253 & 24.8 & $160^{*}$ & 15.7 & \\
\hline Age & & & & & & & & & $<0.001$ \\
\hline $6-12 y$ & 545 & 38.9 & 329 & 23.5 & $325^{*}$ & 23.2 & $203^{*}$ & 14.5 & \\
\hline $13-18 y$ & 160 & 25.4 & 74 & 11.7 & $159^{*}$ & 25.2 & $237^{*}$ & 37.6 & \\
\hline Teacher's attitude & & & & & & & & & $<0.001$ \\
\hline Allow & 89 & 25.4 & 47 & 13.4 & $101^{*}$ & 28.9 & $113^{*}$ & 32.3 & \\
\hline Prohibit & 608 & 36.6 & 352 & 21.2 & $378^{*}$ & 7.8 & $324^{*}$ & 19.5 & \\
\hline School's attitude & & & & & & & & & $<0.001$ \\
\hline Allow & 256 & 29.2 & 144 & 16.4 & 218 & 24.9 & $258^{*}$ & 29.5 & \\
\hline Prohibit & 438 & 38.6 & 257 & 22.7 & 260 & 22.9 & $179^{*}$ & 15.8 & \\
\hline Sedentary behavior $(\mathrm{h} / \mathrm{d})$ & 5.28 & 0.17 & 5.16 & 0.21 & 5.49 & 0.19 & 5.56 & 0.21 & 0.479 \\
\hline Fruit intake (portion/d) & 1.29 & 0.05 & 1.21 & 0.05 & 1.19 & 0.04 & 1.33 & 0.05 & 0.805 \\
\hline Vegetable intake (portion/d) & 2.19 & 0.06 & 1.87 & 0.07 & 1.88 & 0.06 & 2.08 & 0.07 & 0.091 \\
\hline Meat intake (portion/d) & 1.58 & 0.05 & 1.44 & 0.06 & 1.67 & 0.07 & 2.13 & 0.08 & $<0.001$ \\
\hline BMI $\left(\mathrm{kg} / \mathrm{m}^{2}\right)^{\mathrm{a}}$ & 17.47 & 0.14 & 17.11 & 0.16 & $18.12^{*}$ & 0.16 & $19.43^{*}$ & 0.18 & $<0.001$ \\
\hline $\mathrm{WC}(\mathrm{cm})^{\mathrm{b}}$ & 62.76 & 0.39 & 62.11 & 0.51 & $64.89^{*}$ & 0.48 & $69.00 *$ & 0.18 & $<0.001$ \\
\hline $\mathrm{TC}(\mathrm{mmol} / \mathrm{L})^{\mathrm{c}}$ & 4.25 & 0.03 & 4.34 & 004 & 4.29 & 0.04 & 4.18 & 0.04 & 0.03 \\
\hline $\mathrm{LDL}-\mathrm{C}(\mathrm{mmol} / \mathrm{L})^{\mathrm{d}}$ & 2.34 & 0.03 & $2.45^{*}$ & 0.03 & 2.38 & 0.03 & 2.30 & 0.03 & $<0.001$ \\
\hline $\mathrm{TG}(\mathrm{mmol} / \mathrm{L})^{\mathrm{e}}$ & 0.86 & 0.01 & 0.84 & 0.01 & 0.91 & 0.02 & $0.96^{*}$ & 0.03 & $<0.001$ \\
\hline HDL-C $(\mathrm{mmol} / \mathrm{L})^{\mathrm{f}}$ & 1.38 & 0.01 & $1.43^{*}$ & 0.01 & 1.38 & 0.02 & $1.32^{*}$ & 0.31 & $<0.001$ \\
\hline $\mathrm{SBP}(\mathrm{mmHg})^{\mathrm{g}}$ & 96.82 & 0.37 & 95.78 & 0.45 & 97.23 & 0.42 & $99.60^{*}$ & 0.48 & $<0.001$ \\
\hline DBP $(\mathrm{mmHg})^{\mathrm{h}}$ & 61.56 & 0.28 & 61.37 & 0.20 & 61.76 & 0.30 & 63.36 & 0.34 & $<0.000$ \\
\hline $\mathrm{FSG}(\mathrm{mmol} / \mathrm{L})^{\mathrm{i}}$ & 4.57 & 0.03 & 4.55 & 0.02 & 4.62 & 0.03 & 4.61 & 0.03 & 0.227 \\
\hline
\end{tabular}

${ }^{\mathrm{a}} \mathrm{BMI}=$ Body mass index

${ }^{\mathrm{b}} \mathrm{WC}=$ Waist circumference

${ }^{\mathrm{c}} \mathrm{TC}=$ Total cholesterol

${ }^{\mathrm{d}}$ LDL-C $=$ low-density lipid protein cholesterol

${ }^{\mathrm{e}} \mathrm{TG}=$ Triglyceride

${ }^{\mathrm{f}} \mathrm{HDL}=$ High-density lipid protein cholesterol

${ }^{g}$ SBP $=$ Systolic blood pressure

${ }^{\mathrm{h}} \mathrm{DBP}=$ Diastolic blood pressure

${ }^{\mathrm{i}} \mathrm{FSG}=$ Fasting serum glucose

*The pair-wise difference was significant in contrast with that of the non-drinkers at 0.05 level.

age of SSB consumption per day and a lower percentage of non-drinkers than those whose SSB drinking behaviors were prohibited by their teachers and schools. When the nutritional characteristics was analyzed, the differences of nutrition status and lipid profile were displayed among children with different SSB consumption levels; those who drank more than $120 \mathrm{~mL} /$ day had a significantly higher BMI, waist circumfer- ence, and levels of TG and HDL-C than non-drinkers. No significant differences were observed in fruit and vegetable consumption, sedentary behavior, and fasting serum glucose levels between these groups.

\section{SSB Consumption and Risk of Nutrition-Related Cardiovascular Risk Factors}

Considering nutrition-related cardiovascular risk 
Table 3. Odds ratios of cardiovascular risk factors in children and adolescents in sugar-sweetened beverages of each Quartiles.

\begin{tabular}{|c|c|c|c|c|c|c|c|}
\hline & \multicolumn{6}{|c|}{ Quartiles of SSB intake } & \\
\hline & $\begin{array}{c}\text { Prevalence } \\
(\%)\end{array}$ & $\begin{array}{l}\text { Crude OR } \\
(95 \% \mathrm{CI})\end{array}$ & $\begin{array}{c}\text { Adjusted OR } \\
(95 \% \mathrm{CI})\end{array}$ & $\begin{array}{c}\text { Prevalence } \\
(\%)\end{array}$ & $\begin{array}{l}\text { Crude OR } \\
(95 \% \mathrm{CI})\end{array}$ & $\begin{array}{c}\text { Adjusted OR } \\
(95 \% \mathrm{CI})\end{array}$ & \\
\hline Obesity & 7.9 & 1.00 & 1.00 & 6.5 & $0.80(0.49,1.29)$ & $1.06(0.59,1.34)$ & \\
\hline Hypertension & 10.2 & 1.00 & 1.00 & 10.2 & $0.99(0.66,1.49)$ & $1.09(0.64,1.85)$ & \\
\hline Hypertriglyceridemia & 4.4 & 1.00 & 1.00 & 4.0 & $0.90(0.50,1.67)$ & $0.76(0.37,1.58)$ & \\
\hline Hypercholesterolemia & 10.5 & 1.00 & 1.00 & 15.6 & $1.58(1.10,2.27)$ & $1.81(1.15,2.85)$ & \\
\hline High LDL-C Level $^{\text {b }}$ & 7.0 & 1.00 & 1.00 & 9.9 & $1.48(0.95,2.28)$ & $1.62(0.95,2.77)$ & \\
\hline Low HDL-C Level $^{c}$ & 12.6 & 1.00 & 1.00 & 10.7 & $0.83(0.56,1.22)$ & $0.96(0.59,1.58)$ & \\
\hline \multirow{3}{*}{$\operatorname{Met}^{\text {e }}$} & \multicolumn{6}{|c|}{ Quartiles of SSB intake } & \multirow{3}{*}{$P_{\text {trend }}$} \\
\hline & \multicolumn{3}{|c|}{$-120 \mathrm{ml} /$ day } & \multicolumn{3}{|c|}{$\geq 120 \mathrm{ml} /$ day } & \\
\hline & $\begin{array}{c}\text { Prevalence } \\
(\%)\end{array}$ & $\begin{array}{l}\text { Crude OR } \\
(95 \% \mathrm{CI})\end{array}$ & $\begin{array}{c}\text { Adjusted OR } \\
(95 \% \mathrm{CI})\end{array}$ & $\begin{array}{c}\text { Prevalence } \\
(\%)\end{array}$ & $\begin{array}{l}\text { Crude OR } \\
(95 \% \mathrm{CI})\end{array}$ & $\begin{array}{c}\text { Adjusted OR } \\
(95 \% \mathrm{CI})\end{array}$ & \\
\hline Obesity & 9.3 & $1.19(0.79,1.79)$ & $1.08(0.61,1.90)$ & 11.6 & $1.51(1.02,2.27)$ & $2.08(1.21,3.54)$ & 0.024 \\
\hline Overweight & 10.7 & $1.05(0.73,1.54)$ & $1.25(0.79,1.99)$ & 14.8 & $1.52(1.06,2.18)$ & $1.56(0.97,2.52)$ & 0.033 \\
\hline Abdominal obesity & 21.7 & $1.19(0.89,1.59)$ & $1.18(0.81,1.72)$ & 25.5 & $1.50(1.10,1.95)$ & $1.83(1.25,2.69)$ & 0.006 \\
\hline Hypertension & 8.3 & $0.79(0.53,1.19)$ & $0.81(0.47,1.38)$ & 11.1 & $1.10(0.75,1.62)$ & $1.19(0.70,2.02)$ & 0.975 \\
\hline Hypertriglyceridemia & 4.8 & $1.60(0.98,2.59)$ & $1.18(0.63,2.20)$ & 7.3 & $1.71(1.03,2.84)$ & $1.70(1.02,3.06)$ & 0.045 \\
\hline
\end{tabular}

${ }^{a}$ Adjusted OR have adjusted age, gender, physical activities, sedentary behavior and dietary information.

${ }^{\mathrm{b}} \mathrm{LDL}-\mathrm{C}=$ low-density lipid protein cholesterol

${ }^{\mathrm{c}} \mathrm{HDL}-\mathrm{C}=$ High-density lipid protein cholesterol.

${ }^{\mathrm{d}} \mathrm{FSG}=$ Fasting serum glucose

${ }^{\mathrm{e}} \mathrm{Met} \mathrm{S}=$ Metabolic syndrome

Bold text: Significant OR was revealed at 0.05 level.

factor including obesity, dyslipidemia, pre-hypertension, and high fasting glucose levels as dependent variables and SSB consumption as the independent variable, the results of logistic analyses are displayed in Table 3. After adjustment of age, gender, physical activities, sleeping duration, sedentary behavior, and dietary information, children having more SSB per day had significantly higher rates of obesity. SSB consumption more than $120 \mathrm{~mL} /$ day was associated with a 108\% higher risk of obesity [odds ratio (OR): 2.08, 95\% CI: $1.21-3.54$ ], $83 \%$ of abdominal obesity (OR: 1.83, 95\% CI: $1.25-2.69)$, and $70 \%$ of hypertriglyc- eridemia (OR: 1.70, 95\% CI: 1.02-3.06).

\section{Discussion}

Studies in adults have demonstrated that excessive SSB consumption would largely contribute to weight gain and elevated risk of cardiovascular disorders, such as hypertension, MetS, and diabetes ${ }^{24-26)}$. However, studies regarding the relationship between SSB consumption and the risks of obesity and cardiometabolic risk factors were insufficient in Chinese children. In the present study, we analyzed daily SSB con- 
sumption in children living in South China and observed that excessive SSB consumption greatly contributed to increased BMI, WC and TG levels, increased risk of obesity (including abdominal obesity), and hypertriglyceridemia in children aged between 7 and 18 years.

The per capita daily SSB consumption was 90.45 $\pm 3.55 \mathrm{~mL}$ in this study. Compared with the data of other countries, daily SSB consumption was more than $63 \mathrm{~mL}$ in $9-14$ years old Korean children, but much lower than $127 \mathrm{~mL}$ in 2-16 years old Australian children $^{27)}$. In addition, the current study suggested that 65.3\% Chinese children had at least one SSB serving per week, while only $9.5 \%$ had one or more SSB servings per day. Nevertheless, the data from 2009 and 2010 reported that $64.3 \%$ youth had daily SSB consumption in the United States, which was much higher than the consumption in Chinese children ${ }^{28)}$. These findings revealed that the SSB consumption by children was quite lower in Asian countries than in Western countries, which can be partly explained by regional disparities in the dietary pattern.

The present study has shown that over $120 \mathrm{~mL}$ SSB consumption per day would contribute to elevated values of BMI and WC. Besides, it was estimated that over $120 \mathrm{~mL}$ of SSB consumption per day would lead to an increase in the risk of obesity and abdominal obesity by 1.8 and 1.6 times, respectively, in Chinese children, which suggests a positive relationship between excessive SSB consumption and the risk of obesity. This finding was similar to a previous study in American children ${ }^{15)}$. Additionally, previous studies in Chinese children have demonstrated that high and regular SSB consumption was associated with higher prevalence of obesity ${ }^{29)}$, which is consistent with our findings. Because SSB are energy-dense foods with a low satiety and has an incomplete compensation for energy intake, it leads to excessive energy intake and weight gain ${ }^{11)}$.

Meanwhile, convincing evidences in adults also suggested that SSB consumption was associated with other cardiovascular risk factors, such as hypertension $^{25)}$, type 2 diabetes ${ }^{24)}$, Met $S^{26)}$, elevated TG level, and decreased HDL-C level ${ }^{30)}$, implying that excessive SSB consumption enhances the risk of cardio-metabolic disorders. However, the conclusions were inconsistent in children and adolescents. In this study, the positive association between high SSB consumption and risk of hypertriglyceridemia was revealed. High SSB consumption was associated with an increased triglyceride and decreased HDL-C levels. These findings are consistent with a previous study conducted in children ${ }^{31)}$. Most studies supported that when fructose is added to SSB, it would have a detrimental effect on metabolism and thus, increases cardio-metabolic risks ${ }^{32,33)}$. The underlying mechanism might be that increased intake of fructose enhances TG synthesis by providing glycerol and acyl in fructose catabolism ${ }^{34)}$. However, no significant associations were observed between SSBs consumption and hypertension, MetS, and impaired fasting glucose levels in this study as well as in previous studies conducted in children. It is unclear whether SSB consumption leads to the occurrence of these risk factors in childhood.

Although SSB consumption in Chinese children was quite lower than that in American children in the current study, it might increase in the future with rapid economic development. Excessive SSB consumption would bring about serious health problems. Hence, preventive measures to reduce SSB consumption in Chinese children should be carried out. Approaches to limited access to SSB and advertising of SSB was adopted in several countries, such as Australia and Britain ${ }^{16,35)}$; however, there was a lack of valid policies in China. In this study, teachers' and schools' attitudes were strongly associated with SSB consumption of Chinese children. This could be explained by the fact that Chinese children spent most of their time at school and were largely influenced by the school, teacher, as well as their classmates. Consequently, advices from teachers and schools would be a great help for lifestyle establishment in Chinese children, apart from similar policies in other countries.

Several limitations in our study need to be mentioned. Firstly, because this was a cross-sectional study, the causal sequence underlying the relationships between iron metabolic parameters and dyslipidemia can hardly be detected. Secondly, the self-reported questionnaire were used to collect data on physical activities and dietary information of the previous week. Hence, the data might be affected by memory bias. However, using self-reported questionnaire to collect data is practical and eligible for application in a large population study among children. Also, given that the risk is affected by not only teachers' and schools' attitudes but also parents' attitudes, further study on the effect of parents' attitude is required.

\section{Conclusions}

In conclusion, excessive SSB consumption is positively associated with higher risks of obesity (including abdominal obesity) and hyper hypertriglyceridemia in children living in South China, which suggests that SSB consumption in children should be controlled. Besides, because teachers' and schools' attitudes may impact SSB consumption in Chinese children, promoting healthy lifestyle in schools may be effective in reducing obesity and other cardiovascular 
risk factors in these children.

\section{Conflict of Interest Disclosure}

The authors declared no potential conflict of interest.

\section{Funding}

This project has been funded by National Natural Science Foundation of China (Grant No.81302424), Guangdong Provincial Natural Science Foundation (Grant No.2015A030313175), Specialized Research Fund for the Doctoral Program of Higher Education of China (Grant No.20130171120056), Special Research Grant for Non-profit Public Service of the Ministry of Health of China (Grant No. 201202010), and the Fundamental Research Funds for the Central Universities in SYSU (Grant No. 15ykpy09). The funders had no role in study design, data collection and analysis, decision to publish, or preparation of the manuscript.

\section{Reference}

1) Xi B, Bovet P, Hong YM, Zong X, Chiolero A, Kim HS, Zhang $\mathrm{T}$ and Zhao M: Recent blood pressure trends in adolescents from China, Korea, Seychelles and the United States of America, 1997-2012. Journal of hypertension, 2016; 34: 1948-1958

2) Han JC, Lawlor DA and Kimm SY: Childhood obesity. Lancet, 2010; 375: 1737-1748

3) Lee AM, Gurka MJ and DeBoer MD: Trends in Metabolic Syndrome Severity and Lifestyle Factors Among Adolescents. Pediatrics, 2016; 137: e20153177

4) Sun H, Ma Y, Han D, Pan CW and Xu Y: Prevalence and trends in obesity among China's children and adolescents, 1985-2010. PloS one, 2014; 9: e105469

5) Liang YJ, Xi B, Hu YH, Wang C, Liu JT, Yan YK, Xu T and Wang RQ: Trends in blood pressure and hypertension among Chinese children and adolescents: China Health and Nutrition Surveys 1991-2004. Blood pressure, 2011; 20: $45-53$

6) Ding W, Dong $\mathrm{H}$ and Mi J: [Prevalence of dyslipidemia in Chinese children and adolescents: a Meta-analysis]. Zhonghua liu xing bing xue za zhi=Zhonghua liuxingbingxue zazhi, 2015; 36: 71-77

7) Fu JF, Liang L, Gong CX, Xiong F, Luo FH, Liu GL, Li P, Liu L, Xin Y, Yao H, Cui LW, Shi X, Yang Y, Chen LQ and Wei HY: Status and trends of diabetes in Chinese children: analysis of data from 14 medical centers. World journal of pediatrics: WJP, 2013; 9: 127-134

8) Ye P, Yan Y, Ding W, Dong H, Liu Q, Huang G and Mi J: [Prevalence of metabolic syndrome in Chinese children and adolescents: a Meta-analysis]. Zhonghua liu xing bing xue za zhi=Zhonghua liuxingbingxue zazhi, 2015; 36: 884-888
9) Johns DJ, Lindroos AK, Jebb SA, Sjostrom L, Carlsson LM and Ambrosini GL: Dietary patterns, cardiometabolic risk factors, and the incidence of cardiovascular disease in severe obesity. Obesity, 2015; 23: 1063-1070

10) Scharf RJ and DeBoer MD: Sugar-Sweetened Beverages and Children's Health. Annual review of public health, 2016; 37: 273-293

11) Pereira MA: Sugar-sweetened and artificially-sweetened beverages in relation to obesity risk. Advances in nutrition, 2014; 5: 797-808

12) $\mathrm{Hu} \mathrm{FB}$ and Malik VS: Sugar-sweetened beverages and risk of obesity and type 2 diabetes: epidemiologic evidence. Physiology \& behavior, 2010; 100: 47-54

13) Stanhope KL: Sugar consumption, metabolic disease and obesity: The state of the controversy. Critical reviews in clinical laboratory sciences, 2016; 53: 52-67

14) Newby PK, Peterson KE, Berkey CS, Leppert J, Willett WC and Colditz GA: Beverage consumption is not associated with changes in weight and body mass index among low-income preschool children in North Dakota. J Am Diet Assoc, 2004; 104: 1086-1094

15) Ludwig DS, Peterson KE and Gortmaker SL: Relation between consumption of sugar-sweetened drinks and childhood obesity: a prospective, observational analysis. Lancet, 2001; 357: 505-508

16) Veerman JL, Sacks G, Antonopoulos N and Martin J: The Impact of a Tax on Sugar-Sweetened Beverages on Health and Health Care Costs: A Modelling Study. PloS one, 2016; 11: e0151460

17) Chen Y, Ma L, Ma Y, Wang H, Luo J, Zhang X, Luo C, Wang H, Zhao H, Pan D, Zhu Y, Cai L, Zou Z, Yang W, Ma J and Jing J: A national school-based health lifestyles interventions among Chinese children and adolescents against obesity: rationale, design and methodology of a randomized controlled trial in China. BMC public health, 2015; $15: 210$

18) Group of China Obesity Task F: [Body mass index reference norm for screening overweight and obesity in Chinese children and adolescents]. Zhonghua liu xing bing xue za zhi=Zhonghua liuxingbingxue zazhi, 2004; 25: 97-102

19) Ji CY: Report on childhood obesity in China (1)--body mass index reference for screening overweight and obesity in Chinese school-age children. Biomedical and environmental sciences: BES, 2005; 18: 390-400

20) Ma GS, Ji CY, Ma J, Mi J, Yt Sung R, Xiong F, Yan WL, Hu XQ, Li YP, Du SM, Fang HY and Jiang JX: Waist circumference reference values for screening cardiovascular risk factors in Chinese children and adolescents. Biomedical and environmental sciences: BES, 2010; 23: 21-31

21) Cook S, Auinger P, Li C and Ford ES: Metabolic syndrome rates in United States adolescents, from the National Health and Nutrition Examination Survey, 19992002. The Journal of pediatrics, 2008; 152: 165-170

22) National High Blood Pressure Education Program Working Group on High Blood Pressure in C and Adolescents: The fourth report on the diagnosis, evaluation, and treatment of high blood pressure in children and adolescents. Pediatrics, 2004; 114: 555-576

23) Yoon JM: Dyslipidemia in children and adolescents: when and how to diagnose and treat? Pediatric gastroenterology, 
hepatology \& nutrition, 2014; 17: 85-92

24) Teshima N, Shimo M, Miyazawa K, Konegawa S, Matsumoto A, Onishi Y, Sasaki R, Suzuki T, Yano Y, Matsumoto K, Yamada T, Gabazza EC, Takei Y and Sumida Y: Effects of sugar-sweetened beverage intake on the development of type 2 diabetes mellitus in subjects with impaired glucose tolerance: the Mihama diabetes prevention study. Journal of nutritional science and vitaminology, 2015; 61: 14-19

25) Jayalath VH, de Souza RJ, Ha V, Mirrahimi A, BlancoMejia S, Di Buono M, Jenkins AL, Leiter LA, Wolever TM, Beyene J, Kendall CW, Jenkins DJ and Sievenpiper JL: Sugar-sweetened beverage consumption and incident hypertension: a systematic review and meta-analysis of prospective cohorts. The American journal of clinical nutrition, 2015; 102: 914-921

26) Ejtahed HS, Bahadoran Z, Mirmiran P and Azizi F: Sugar-Sweetened Beverage Consumption Is Associated with Metabolic Syndrome in Iranian Adults: Tehran Lipid and Glucose Study. Endocrinology and metabolism, 2015; 30: 334-342

27) Clifton PM, Chan L, Moss CL, Miller MD and Cobiac L: Beverage intake and obesity in Australian children. Nutrition \& metabolism, 2011; 8: 87

28) Kit BK, Fakhouri TH, Park S, Nielsen SJ and Ogden CL: Trends in sugar-sweetened beverage consumption among youth and adults in the United States: 1999-2010. The American journal of clinical nutrition, 2013; 98: 180-188

29) Shang XW, Liu AL, Zhang Q, Hu XQ, Du SM, Ma J, Xu GF, Li Y, Guo HW, Du L, Li TY and Ma GS: Report on childhood obesity in China (9): sugar-sweetened beverages consumption and obesity. Biomedical and environmental sciences: BES, 2012; 25: 125-132

30) Hernandez-Cordero S, Barquera S, Rodriguez-Ramirez S, Villanueva-Borbolla MA, Gonzalez de Cossio T, Dom- marco JR and Popkin B: Substituting water for sugarsweetened beverages reduces circulating triglycerides and the prevalence of metabolic syndrome in obese but not in overweight Mexican women in a randomized controlled trial. The Journal of nutrition, 2014; 144: 1742-1752

31) Van Rompay MI, McKeown NM, Goodman E, Eliasziw M, Chomitz VR, Gordon CM, Economos CD and Sacheck JM: Sugar-Sweetened Beverage Intake Is Positively Associated with Baseline Triglyceride Concentrations, and Changes in Intake Are Inversely Associated with Changes in HDL Cholesterol over 12 Months in a Multi-Ethnic Sample of Children. The Journal of nutrition, 2015; 145: 2389-2395

32) Richelsen B: Sugar-sweetened beverages and cardio-metabolic disease risks. Current opinion in clinical nutrition and metabolic care, 2013; 16: 478-484

33) Vos MB, Kaar JL, Welsh JA, Van Horn LV, Feig DI, Anderson CA, Patel MJ, Cruz Munos J, Krebs NF, Xanthakos SA, Johnson RK, American Heart Association Nutrition Committee of the Council on L, Cardiometabolic H, Council on Clinical C, Council on Cardiovascular Disease in the Y, Council on C, Stroke N, Council on E, Prevention, Council on Functional G, Translational B and Council on H: Added Sugars and Cardiovascular Disease Risk in Children: A Scientific Statement From the American Heart Association. Circulation, 2016;

34) Basciano H, Federico L and Adeli K: Fructose, insulin resistance, and metabolic dyslipidemia. Nutrition \& metabolism, 2005; 2: 5

35) Elliott-Green A, Hyseni L, Lloyd-Williams F, Bromley H and Capewell S: Sugar-sweetened beverages coverage in the British media: an analysis of public health advocacy versus pro-industry messaging. BMJ open, 2016; 6: e011295 